\title{
Suggestion and Refusal Strategies in English by Kurdish Undergraduate Students
}

\author{
Yaseen Alzeebaree ${ }^{1,2} \&$ Mehmet Ali Yavuz ${ }^{2}$ \\ ${ }^{1}$ Nawroz University, College of Languages, Department of English, Iraq \\ ${ }^{2}$ Cyprus International University, Faculty of Education, Department of English Language, 99258 Lefkoşa, via \\ Mersin 10, Turkey \\ Correspondence: Yaseen Alzeebaree, Nawroz University, College of Languages, Department of English, Iraq. \\ E-mail: yassin.teacher@gmail.com
}

Received: April 27, 2018 Accepted: May 17, 2018 Online Published: June 9, 2018

doi:10.5539/ijel.v8n5p151 URL: https://doi.org/10.5539/ijel.v8n5p151

\begin{abstract}
This paper investigated the sociopragmatic and pragmalinguistic competence of Kurdish EFL undergraduate students through the speech acts of suggestion and refusal. Eighty-three Kurdish EFL undergraduate students and 14 native speakers of English participated in the study. Data were elicited using a Discourse Completion Task consisting of three suggestive and three refusal situations, and the responses were rated on a scale developed by the researcher. The response data for suggestions and refusals were coded according to the taxonomies of Martinez-Flor (2005) and Beebe et al. (1990), respectively. All statistical analyses were performed using SPSS version 22. Four researchers rated the Kurdish EFL undergraduate students' responses in terms of appropriate pragmatic and linguistic forms. The results of the study revealed differences in the overall strategies and strategy patterns between the responses of Kurdish EFL undergraduate students and Native speakers of English groups, as well as differences between students of state and private universities.
\end{abstract}

Keywords: pragmatic, suggestion, refusal, taxonomy of suggestion and refusal

\section{Introduction}

\subsection{Introduction of the Problem}

Pragmatic competence has gained more importance in English as a Foreign Language (EFL) studies. The pragmatic aspect of language emphasizes the appropriate use of language in different discourse contexts (Thomas, 1983). Yule (1996) defines pragmatics as the study of meaning communicated by a speaker (or writer) and interpreted by a listener (or reader). Misunderstanding in communication does not often result from a lack of linguistic competence, but from a lack of pragmatic competence. When L2 (second language) learners fail to recognize and utilize appropriate and correct speech patterns, they are prone to causing misunderstandings and communication breakdowns. Moreover, they run the risk of unintentionally offending native language speakers. Thus, the proper use of speech acts plays a vital role in successful interpersonal communication.

A speech act is the functional aspect of language. Austin (1975), who first used the phrase in this context, argued that speakers do not only make statements with their words; the speaker's utterance is itself an action. According to Austin (1962), an utterance has three types of meaning: the first is the propositional or locutionary meaning. The locutionary meaning comprises the actual words of an utterance-i.e., its literal meaning. The locutionary meaning states or describes a fact, as in the example, 'It is hot in here'. In addition to having a literal meaning, a well-structured utterance has an intended purpose (and sometimes a hidden meaning). This is an utterance's second type of meaning, known as an illocutionary act. Saying 'It is hot in here' may mean more than a statement of a condition. It may be a request to open a window, turn on an air conditioner, etc. It could also be a complaint, if for instance the utterance is reiterated. Finally, the third kind of meaning is perlocutionary. It is the effect of a speech act on the hearer (McKay \& Hornberger, 1996). According to Austin (1962), the terms 'speech act' and 'illocutionary act' are similar in meaning. Moreover, the meanings of speech act, illocutionary act, illocutionary force, pragmatic force (or just force), all are alike.

Performing speech acts involves both sociocultural and sociolinguistic knowledge. While sociocultural knowledge determines when to perform a speech act and which one is appropriate for a situation, sociolinguistic 
knowledge determines the actual linguistic realization of each speech act (Cohen, 1996). Mastering structure and lexicon alone is not sufficient to communicate successfully and effectively. Language learners must develop a grammatical or linguistic competence as well as a communicative or pragmatic competence in order to communicate effectively, especially when communicating across cultures.

\subsection{Speech Acts of Suggestion}

We usually face different suggestive situations. Suggestion is a very important speech act in our daily life. Suggestion belongs to the directive group of speech acts. Searle (1976) defines suggestions as directive speech acts through which the addresser aims to get the addressee to commit him/herself to some future course of action. Directive speech acts are subdivided into impositive and non-impositive directives (Haverkate, 1984). The former group incorporates threatening speech acts, such as ordering, pleading and requesting, while the latter group encompasses suggestions and instructions. The difference between these two groups is that the performance of an impositive speech act is intended to benefit of the speaker, whereas performing a non-impositive speech act is meant to benefit the hearer (Martinez-Flor \& Uso-Juan, 2010).

According to Brown and Levinson's (1987) politeness theory, suggestions are performed to advantage the hearer. However, there is a kind of imposition on the hearer by affronting his/her negative face in performing suggestions (Banerjee \& Carrell, 1988). In essence, the speaker interferes with the hearer's life when making suggestions. Therefore, the speech act of suggestion is considered as a face-threatening act (FTA). Consequently, using certain politeness strategies can soften, mitigate, or minimize the effect/offensiveness of suggestions on the hearer.

Table 1. A taxonomy of suggestion linguistic realization strategies (Martinez-Flor, 2005, p. 175)

\begin{tabular}{lll}
\hline Type & Strategy & Example \\
\hline Direct & Performative verb & I suggest that you... \\
& & I advise you to... \\
& I recommend that you... \\
& Noun of suggestion & My suggestion would be... \\
& Imperative & Try using... \\
& Negative imperative & Don't try to... \\
\hline Conventionalized Forms & Specific formulae & Why don't you...? \\
& (interrogative forms) & How about ...? \\
& & What about ...? \\
& Possibility/ probability & Have you thought about...? \\
& You can... \\
& You could... \\
& You may... \\
& Should & you might... \\
& Need & You should... \\
& Conditional & You need... \\
& Impersonal & If I were you, I would... \\
& One thing (that you can do) \\
& would be... \\
& Here's one possibility... \\
& There are a number of \\
& options that you... \\
& It would be helpful if you... \\
& It might be better to... \\
& A good idea would be... \\
& It would be nice if... \\
& I've heard that... \\
&
\end{tabular}

The Martinez-Flor taxonomy, as seen above in Table 1, exemplifies various strategies of suggestion according to three overarching categories: (a) direct strategies, in which the speaker clearly states what he/she means; (b) conventionalized forms, in which the intended meaning of suggestion is understandable but not as direct and clear as the first strategy; and indirect forms. 


\subsection{Speech Acts of Refusal}

Research conducted on the speech act of refusals fall into two types: those that investigated the strategies employed by native speakers of a certain language when refusing, and those that explored the refusal behaviour of non-native speakers.

The speech act of refusal is a significant subject in discourse pragmatics studies (Fraser, 1990; Wannaruk, 2008). Refusals are used to reject the speech acts of requests, invitations, suggestions, offers, etc., and occur regularly in communication (Sadler \& Eroz, 2001). Although refusal acts occur in every culture and language, cross-cultural studies have revealed differences not only in the ways different cultures express rejections, but also in how they show politeness when doing so. Culture thus plays a key role in selecting the strategies used to perform a refusal.

Refusals, which can damage the face of the speaker and the addressee, are categorised as face-threatening acts. Al-Kahtani (2005) claims that uttering 'no' is hard for non-native speakers of a language. Refusals are delicate speech acts to perform. Refusing a request can be uncomfortable for the respondent who refused what was asked of them as well as for the asker who was refused. Speakers who can effectively utilise politeness strategies and indirect strategies are better able to mitigate face threats and save face for both participants. In doing so, they avoid potential failures in their interpersonal relationships.

According to the Beebe et al. taxonomy of refusals (1990), there are three direct strategies and eleven indirect strategies that may be used in performing a speech act of refusals.

The three direct strategies of refusals are:

1. Performative ('I refuse')

2. Non-performative ('No')

3. Negative willingness ability ('I can't')

The eleven indirect strategies are:

1. Statement of regret ('I'm sorry')

2. Wish ('I wish I could help you')

3. Excuse, reason, or explanation ('I am sick')

4. Statement of alternative

5. Set condition for future/past acceptance ('If I had enough money')

6. Promise of future acceptance ('I'll do it next time')

7. Statement of principle ('I never drink right after dinner')

8. Statement of philosophy ('One can't be too careful')

9. Attempt to dissuade the interlocutor

10. Acceptance that functions as a refusal

11. Avoidance

Han (2016) conducted a study on how lower-intermediate and upper intermediate level Turkish EFL learners realize refusals in English. Data were collected through role-plays. The results showed that the participants frequently preferred indirect refusal strategies to direct ones, Turkish EFL learners performed pragmatic transfers while using refusal strategies, and L1 (first language) pragmatic transfers decreases with an increase in EFL proficiency. Furthermore, EFL learners in both groups gave greater importance to status than native English speakers did.

Lin (2014) conducted a study on 30 native speakers of Mandarin Chinese in Taiwan (NSC), 30 Chinese EFL learners in Taiwan, and 30 native speakers of American English in America to examine the cross-cultural differences between Chinese and English refusals. The results displayed similarities and differences between Chinese and English refusals. As for EFL learners, they tended to perceive the face-threat greater thank native NSE. They also used more strategies and softening devices than non-EFL Chinese speakers and Americans.

Moaveni (2014) conducted a study to examine the difference in refusal strategies between sixteen American undergraduates and thirty-two international college students. Moaveni's study also investigated potential variations with respect to gender. The findings of the research show that all participants favoured direct strategies. Abed (2011) investigated the pragmatic transfer of refusal strategies of request, offer and suggestion, and invitation between Iraqi native speakers of Arabic and American native speakers of English. The results suggest 
a difference between the ways Iraqi EFL learners and American NSE employ these strategies. Iraqi EFL learners tend to use statements of reason/explanation, regret, wish, and refusal adjuncts more often than American NSE. Americans are more careful with respect to interlocutors of higher and equal status, whereas Iraqi EFL learners pay more attention to lower status. Males differ slightly from females in refusal frequency and adjuncts.

\section{Method}

This study examined KEFLUS development of L2 pragmatic competence by investigating their performance of the speech acts of suggestion and refusal. The study addressed the following questions:

1) What similarities and differences arise when observing the strategies KEFLUS and NSE employ when making suggestions and refusals?

2) How effective are KEFLUS at choosing appropriate linguistic and pragmatic forms when making suggestions and refusals?

3) Do male and female KEFLUS utilize different strategies when performing the speech acts of suggestion and refusal? If so, how do their strategy patterns differ?

4) Is there a significance difference between private and state universities with regard to their effectiveness at teaching appropriate linguistic and pragmatic forms (such as permission, request, suggestion, opinion, apology, invitation, refusal, offer, questioning, and advising)? If so, how do they differ?

\subsection{Participants}

Table 2. Number of participants of both groups

\begin{tabular}{llll}
\hline Participants & Male & Female & Total \\
\hline Kurdish EFL Undergraduate Students & 33 & 50 & 83 \\
Native Speakers of English & 3 & 11 & 14 \\
\hline Total & 36 & 61 & 97 \\
\hline
\end{tabular}

As seen in Table 2, the KEFLUS study participants consisted of 83 students (33 males and 50 females) from the Iraqi Kurdistan region, and 14 NSE participants ( 3 males and 11 females).

Table 3. Kurdish EFL undergraduate students

\begin{tabular}{|c|c|c|c|c|c|c|c|c|c|c|}
\hline \multirow{2}{*}{ No. } & \multirow{2}{*}{ University } & \multirow{2}{*}{ College } & \multicolumn{4}{|c|}{ Stage } & \multicolumn{2}{|c|}{ Gender } & \multirow{2}{*}{ Age } & \multirow{2}{*}{ Number } \\
\hline & & & $1^{\text {st }}$ & $2^{\text {nd }}$ & $3^{\text {rd }}$ & $4^{\text {th }}$ & Male & Female & & \\
\hline 1 & Duhok & Arts & 6 & 8 & & & 6 & 8 & $19-24$ & 14 \\
\hline 2 & Salahaddin & languages & & & 11 & & 2 & 9 & $19-24$ & 11 \\
\hline 3 & Nawroz & Languages & & & 25 & & 11 & 14 & $19-24$ & 25 \\
\hline 4 & Soran & Arts & 2 & & 3 & 22 & 10 & 17 & $19-24$ & 27 \\
\hline 5 & Zakho & Arts & & & 6 & & 4 & 2 & $19-24$ & 6 \\
\hline Total & & & 8 & 8 & 45 & 22 & 33 & 50 & & 83 \\
\hline
\end{tabular}

Table 3 displays KEFLUS participant ages, genders, universities they attended, and which stages they had reached at the time of the study.

The NSE participants came from the following English-speaking countries: the United Kingdom, the United States, Canada, and Ireland. Among the NSE participants, three had diplomas, two had bachelor's degrees, one had a Ph.D., one had an honorary doctorate, and one had no degree.

\subsection{Data Collection Method}

The Discourse Completion Task (DCT) for this study consisted of six scenarios based on daily life situations. In order to measure the ability of KEFLUS to identify and utilize appropriate linguistic and pragmatic forms when performing a speech act of either suggestion or refusal, the researchers designed a rating system consisting of two questions that rated participant responses based on a five-point Likert scale. For both questions, four qualified and experienced researchers rated the responses based on the following questions:

1. 'Is the participant's response pragmatically appropriate?'

2. 'Is the participant's response grammatically (structurally) correct?' 
For the first question, the evaluators rated the appropriateness of each KEFLUS response from 'entirely inappropriate' (one) to 'entirely appropriate' (five). For the second question, the evaluators rated the correctness of each KEFLUS response from 'strongly disagree' (one) to 'strongly agree' (five).

\subsection{Procedure}

The researcher employed DCT scenarios based on six daily life situations. The six scenarios were translated into the Sorani and Kurmanji dialects of the Kurdish language, and then validated by a Kurdish language instructor before being incorporated into the DCT instrument.

The DCT instrument was then validated by conducting a pilot on a male and female NSE group. Members of the pilot group came from various English-speaking countries and held a variety of academic degrees. After the pilot group had given their feedback on the DCT, the instrument was revised and conducted again on a group of 20 participants. The participants for the final pilot were chosen to be as similar as possible to the target population for the study. Data collected from the participants were analysed based on the taxonomies of suggestion and refusal of Martinez-Flor (2005) and Beebe et al. (1990), respectively.

\subsection{Data Analysis}

Data were analysed both quantitatively and quantitatively by researchers who evaluated the study participants based on their overall strategy use and strategy patterns. Data were analysed using the Statistical Package for the Social Science (SPSS) version 22.

\section{Results}

\subsection{First Research Question}

First Research Question: What similarities and differences arise when observing the strategies KEFLUS and NSE students employ when making suggestions and refusals?

\subsubsection{Suggestion}

The speech act of suggestion belongs to directive speech acts performed to advantage the hearer. It is considered a FTA. The study used the Martinez-Flor (2005) taxonomy of suggestion linguistic realization strategy used as a data coding scheme and analysis method for the suggestion act.

Table 4. Overall strategy used by the two groups (suggestion 1)

\begin{tabular}{lll}
\hline Strategy & KEFLUS & NSE \\
\hline Direct & $58(69.9 \%)$ & $4(28.6 \%)$ \\
Conventionalized forms & $25(30.1 \%)$ & $10(71.4 \%)$ \\
\hline Total & $83(100 \%)$ & $14(100 \%)$ \\
\hline
\end{tabular}

As the data in Table 4 shows, the KEFLUS and NSE groups differed in the types of strategies they chose to employ in the first situation. $71.4 \%$ of the NSE group avoided direct strategies and opted instead for conventionalized forms, such as 'If I were you I'd spend a year travelling. It's good to have a break when you finish school'. Meanwhile, $69.9 \%$ of the KEFLUS group used direct and explicit strategies, such as 'I suggest you complete your study then plan for a journey'.

Table 5. Individual strategies used by the two groups (suggestion 1)

\begin{tabular}{lll}
\hline Strategy & KEFLUS & NSE \\
\hline Direct & & \\
\hline Performative & $46(55.4 \%)$ & $3(21.4 \%)$ \\
Imperative & $8(9.6 \%)$ & $1(7.1 \%)$ \\
Negative imperative & $4(4.8 \%)$ & $0(0 \%)$ \\
\hline Conventionalized Forms & \\
\hline Interrogative forms & $23(27.7 \%)$ & $8(57.1 \%)$ \\
Should & $0(0 \%)$ & $1(7.1 \%)$ \\
Conditional & $2(2.4 \%)$ & $1(7.1 \%)$ \\
\hline Total & $83(100 \%)$ & $14(100 \%)$ \\
\hline
\end{tabular}


Table 5 details the frequency and percentages of strategies used by the two groups, revealing differences in the suggestive behaviours of the KEFLUS and NSE groups. The KEFLUS used direct performative strategies most often $(55.4 \%)$, followed by conventionalized interrogative forms $(27.7 \%)$. By contrast, the NSE group preferred conventional interrogative forms most often (57.1\%), followed by direct performative forms $(21.4 \%)$. The preference of NSE toward interrogative forms could be due in part to a learned understanding of and sensitivity to the importance of face.

Table 6. Overall strategy used by the two groups (suggestion 2)

\begin{tabular}{lll}
\hline Strategy & KEFLUS & NSE \\
\hline Direct & $54(65.1 \%)$ & $5(35.7 \%)$ \\
Conventionalized forms & $29(34.9 \%)$ & $5(35.7 \%)$ \\
Indirect & $0 \%$ & $4(28.6 \%)$ \\
\hline Total & $83(100 \%)$ & $14(100 \%)$ \\
\hline
\end{tabular}

Table 6 shows the overall strategies the KEFLUS and NSE groups employed in the second situation. The KEFLUS again chose direct strategies most often when making suggestions $(65.1 \%)$, while the NSE showed more politeness. The NSE opted for direct and conventionalized strategies in equal numbers $(35.7 \%)$, while $28.6 \%$ chose indirect suggestion strategies.

Table 7. Individual strategies used by the two groups (suggestion 2)

\begin{tabular}{lll}
\hline Strategy & KEFLUS & NSE \\
\hline Direct & & \\
\hline Performative & $35(42.2 \%)$ & $2(14.3 \%)$ \\
Noun of suggestion & $2(2.4 \%)$ & $0(0 \%)$ \\
Imperative & $17(20.5 \%)$ & $2(14.3 \%)$ \\
Negative imperative & $1(1.2 \%)$ & $0(0 \%)$ \\
\hline Conventionalized Forms & & $4(28.6 \%)$ \\
\hline Interrogative forms & $26(31.3 \%)$ & $1(7.1 \%)$ \\
Possibility/probability & $0(0 \%)$ & $1(7.1 \%)$ \\
Should & $2(2.4 \%)$ & $1(7.1 \%)$ \\
Conditional & $0(0 \%)$ & \\
\hline Indirect & & $2(14.3 \%)$ \\
\hline Impersonal & $0(0 \%)$ & $1(7.1 \%)$ \\
Hints & $0(0 \%)$ & $14(100 \%)$ \\
\hline Total & $83(100 \%)$ & \\
\hline
\end{tabular}

Table 7 illustrates the individual strategies of the two groups when performing the speech act of suggestion in the second situation. The KEFLUS opted for performative strategies most frequently (42.2\%), followed by interrogative (31.3\%) and imperative strategies (20.5\%). The NSE showed more competence, and tended toward interrogative forms most often (28\%), followed by imperative (14.3\%) and performative strategies (14.3\%). 21.4\% of the NSE also employed indirect strategies, while the KEFLUS did not employ them at all. These results suggest that KEFLUS in their L2 adopt fewer syntactic types of suggestions than NSE. The data supports Li (2010), who observed that Cantonese L2 students adopted fewer strategies in making suggestions than Australian NSE students.

Table 8. Overall strategy used by the two groups (suggestion 3)

\begin{tabular}{lll}
\hline Strategy & KEFLUS & NSE \\
\hline Direct & $67(80.7 \%)$ & $6(42.9 \%)$ \\
Conventionalized forms & $15(18.1 \%)$ & $6(42.9 \%)$ \\
Indirect & $1(1.2 \%)$ & $2(14.2 \%)$ \\
\hline Total & $83(100 \%)$ & $14(100 \%)$ \\
\hline
\end{tabular}

Table 8 shows the overall strategies the KEFLUS and NSE groups chose to employ in the third situation. The KEFLUS chose direct strategies at the highest percentage yet seen during this study (80.7\%). 18.1\% chose 
conventionalized forms, and just $1.2 \%$ chose an indirect strategy. Meanwhile, the same number of NSE opted for direct and conventionalized strategies (42.9\%), and $14.2 \%$ chose indirect suggestion strategies.

Table 9. Individual strategies used by the two groups (suggestion 3)

\begin{tabular}{lll}
\hline Strategy & KEFLUS & NSE \\
\hline Direct & & \\
\hline Performative & $50(60.2 \%)$ & $2(14.3 \%)$ \\
Imperative & $14(16.9 \%)$ & $4(28.6 \%)$ \\
Negative imperative & $2(2.4 \%)$ & $0(0 \%)$ \\
\hline Conventionalized Forms & & \\
\hline Interrogative forms & $11(13.3 \%)$ & $1(7.1 \%)$ \\
Possibility/probability & $0(0 \%)$ & $2(14.3 \%)$ \\
Should & $4(4.8 \%)$ & $2(14.3 \%)$ \\
Conditional & $1(1.2 \%)$ & $2(14.3 \%)$ \\
\hline Indirect & & \\
\hline Impersonal & $0(0 \%)$ & $1(7.1 \%)$ \\
Hints & $1(1.2 \%)$ & $0(0 \%)$ \\
\hline Total & $83(100 \%)$ & $14(100 \%)$ \\
\hline
\end{tabular}

Table 9 illustrates the individual strategies of the two groups when performing the speech act of suggestion in the third situation. The NSE chose this time to use imperative strategies most often (28.6\%), while the KEFLUS opted most often for performative strategies $(60.2 \%)$, followed by imperative $(16.9 \%)$ and interrogative strategies $(13.3 \%)$.

\subsubsection{Refusal}

Pragmatics studies must also consider the act of refusal (Fraser, 1990; Wannaruk, 2008), which is an important component of communication. Refusal acts are used to reject a request, invitation, suggestion, offer, etc. (Sadler \& Eroz, 2001).

Table 10. Overall strategy used by the two groups (refusal of a request)

\begin{tabular}{lll}
\hline Strategy & Kurdish EFL & NSE \\
\hline Direct & $26(31.3 \%)$ & $3(21.4 \%)$ \\
Indirect & $57(68.7 \%)$ & $11(78.6 \%)$ \\
\hline Total & $83(100 \%)$ & $14(100 \%)$ \\
\hline
\end{tabular}

With regard to the overall refusal strategies, Table 10 demonstrates that the KEFLUS and NSE both opted to utilize direct and indirect strategies at similar rates. Both groups preferred indirect strategies, with $68.7 \%$ of the KEFLUS group opting for them, and 78.6 of the NSE group opting for them.

Table 11. Individual strategies used by the two groups (refusal of a request)

\begin{tabular}{lll}
\hline Strategy & KEFLUS & NSE \\
\hline Direct & & \\
\hline No & $5(6.0 \%)$ & $0(0 \%)$ \\
Negative willingness & $21(25.3 \%)$ & $3(21.4 \%)$ \\
\hline Indirect & & \\
\hline Regret & $10(12.0 \%)$ & $0(0 \%)$ \\
Wish & $1(1.2 \%)$ & $0(0 \%)$ \\
Excuse, reason, explanation & $8(9.6 \%)$ & $3(21.4 \%)$ \\
Regret, reason and Alternative & $12(14.5 \%)$ & $3(21.4 \%)$ \\
Alternative & $2(2.4 \%)$ & $2(14.3 \%)$ \\
Condition & $1(1.2 \%)$ & $0(0 \%)$ \\
Regret and reason & $22(26.5 \%)$ & $3(21.4 \%)$ \\
Regret and alternative & $1(1.2 \%)$ & $0(0 \%)$ \\
\hline Total & $83(100 \%)$ & $14(100 \%)$ \\
\hline
\end{tabular}


Table 11 illustrates the frequency and percentages of individual strategies used by the two groups when performing refusals in the first situation. The KEFLUS employed 'negative willingness' and 'regret and reason' most often and at almost equal rates $(25.3 \%$ and $26.5 \%$, respectively). The NSE chose 'negative willingness', 'excuse/reason/explanation', 'regret/reason/alternative', and 'regret/reason' most often and at equal rates (21.4\%). The data suggests that NSE are more sensitive and/or place higher emphasis on avoiding FTAs. Moreover, participants in both groups who chose a direct strategy tended to avoid 'no' in lieu of 'negative willingness', which may be due in part to an understanding of and sensitivity to the face. According to Chang (2009), 'no' is more face-threatening than 'negative willingness'.

Table 12. Overall strategies used by the two groups (refusal of a suggestion)

\begin{tabular}{lll}
\hline Strategy & KEFLUS & NSE \\
\hline Direct & $50(60.2 \%)$ & $2(14.3 \%)$ \\
Indirect & $32(38.6 \%)$ & $9(64.3 \%)$ \\
Adjuncts & $1(1.2 \%)$ & $3(21.4 \%)$ \\
\hline Total & $83(100 \%)$ & $14(100 \%)$ \\
\hline
\end{tabular}

Table 12 illustrates the overall strategies of the NSE and KEFLUS when performing the second situation of the speech act of refusal. The KEFLUS were more apt to favour a direct strategy and least apt to use adjuncts, whereas the NSE favoured indirect strategies. This data suggests that NSE are more aware of the potential face threat that direct refusal poses.

Table 13. Individual strategies by the two groups (refusal of a suggestion)

\begin{tabular}{lll}
\hline Strategy & KEFLUS & NSE \\
\hline Direct & & $2(14.3 \%)$ \\
No & $14(16.9 \%)$ & $0(0 \%)$ \\
Negative willingness & $36(43.4 \%)$ & \\
\hline Indirect & & $0(0 \%)$ \\
\hline Regret & $11(13.3 \%)$ & $0(0 \%)$ \\
Wish & $2(2.4 \%)$ & $4(28.6 \%)$ \\
Excuse, reason, explanation & $2(2.4 \%)$ & $1(7.1 \%)$ \\
Regret, reason and Alternative & $2(2.4 \%)$ & $1(7.1 \%)$ \\
Alternative & $0(0 \%)$ & $2(14.3 \%)$ \\
Condition & $0(0 \%)$ & $0(0 \%)$ \\
Statement of principle & $2(2.4 \%)$ & $2(14.3 \%)$ \\
Regret and reason & $13(15.7 \%)$ & $0(0 \%)$ \\
Regret and alternative & $0(0 \%)$ & $1(7.1 \%)$ \\
Criticize requester & $0(0 \%)$ & $1(7.1 \%)$ \\
\hline Adjuncts to refusal & & $14(100 \%)$ \\
\hline Positive feeling & $1(1.2 \%)$ & \\
\hline Total & $83(100 \%)$ & \\
\hline
\end{tabular}

Table 13 illustrates the individual strategies of the two groups when performing the speech act of refusal during the second situation. The NSE chose to use indirect strategies most often, specifically favouring 'excuse/reason/explanation' (28.6\%). The KEFLUS chose 'negative willingness' higher than the other strategies (43.4\%), which could be due in part to their lack of pragmatic competence.

Table 14. Overall strategy used by the two groups (refusal of an offer)

\begin{tabular}{lll}
\hline Strategy & KEFLUS & NSE \\
\hline Direct & $49(59.0 \%)$ & $0(0 \%)$ \\
Indirect & $21(25.3 \%)$ & $5(35.7 \%)$ \\
Adjuncts & $13(15.7 \%)$ & $9(64.3 \%)$ \\
Total & $83(100 \%)$ & $14(100 \%)$ \\
\hline
\end{tabular}


Table 14 above shows the overall strategy used by the KEFLUS and NSE when refusing an offer. When refusing, the KEFLUS opted for direct strategies most often (59.0\%), indirect strategies second (25.3\%), and adjuncts least often (15.7). Meanwhile, the NSE preferred adjuncts strategies most often (64.3\%), and indirect strategies second $(35.7 \%)$. The preferences of the NSE suggest a tendency toward politeness as well as indicating a higher pragmatic competence than the KEFLUS.

Table 15. Individual strategies used by the two groups (refusal of an offer)

\begin{tabular}{lll}
\hline Strategy & KEFLUS & NSE \\
\hline Direct & & \\
\hline No & $5(6.0 \%)$ & $0(0 \%)$ \\
Negative willingness & $44(53.0 \%)$ & $0(0 \%)$ \\
\hline Indirect & & \\
\hline Regret & $8(9.6 \%)$ & $0(0 \%)$ \\
Excuse, reason, explanation & $3(3.6 \%)$ & $2(14.3 \%)$ \\
Regret, reason and Alternative & $0(0 \%)$ & $2(14.3 \%)$ \\
Regret and reason & $10(12.0 \%)$ & $1(7.1 \%)$ \\
\hline Adjuncts to refusal & & $4(28.6 \%)$ \\
\hline Positive feeling & $9(10.8 \%)$ & $5(35.7 \%)$ \\
Gratitude/ appreciation & $4(4.8 \%)$ & $14(100 \%)$ \\
\hline Total & $83(100 \%)$ & \\
\hline
\end{tabular}

Table 15 details strategies used by both groups when refusing an offer in the third situation. The results show that the NSE were more careful than the KEFLUS with regard to FTAs. The NSE used the strategies of 'positive feeling' (28.6\%) and 'gratitude/appreciation' (35.7 \%) more than other forms, while the KEFLUS again favoured 'negative willingness' direct refusals (44\%).

\subsection{Second Research Question}

Second Research Question: How effective are KEFLUS at choosing appropriate linguistic and pragmatic forms when making suggestions and refusals?

Two sub-questions were created to investigate the second research question. The first sub-question evaluated the appropriateness of each KEFLUS response from a sociopragamatic point of view: 'Is the participant's response pragmatically (sociopragmatically) appropriate?' Based on this first sub-question, four experienced researchers rated each KEFLUS response from one to five, with one being 'entirely inappropriate' and five being 'entirely appropriate'.

The second sub-question evaluated the appropriateness of each KEFLUS response from a pragmalinguistic point of view: 'Is the participant's response grammatically or structurally (pragmalinguistically) correct?' Based on this first sub-question, four experienced researchers rated each KEFLUS response from one to five, with one being 'strongly disagree' and five being 'strongly agree'.

\subsubsection{Suggestion}

Table 16. Appropriate pragmatic and linguistic forms (suggestion)

\begin{tabular}{|c|c|c|c|c|c|}
\hline \multicolumn{3}{|l|}{ Questions } & Suggestion 1 & Suggestion 2 & Suggestion 3 \\
\hline \multirow[t]{5}{*}{ Sociopragmatics } & \multirow[t]{2}{*}{$\mathrm{N}$} & Valid & 332 & 332 & 332 \\
\hline & & Missing & 0 & 0 & 0 \\
\hline & \multicolumn{2}{|c|}{ Mean } & 2.8373 & 3.3193 & 3.1928 \\
\hline & \multicolumn{2}{|c|}{ Mode } & 3.00 & 3.00 & 3.00 \\
\hline & \multicolumn{2}{|c|}{ Std. Deviation } & 1.22563 & 1.52339 & 1.12867 \\
\hline \multirow[t]{5}{*}{ Pragmalinguistics } & \multirow[t]{2}{*}{$\mathrm{N}$} & Valid & 332 & 332 & 332 \\
\hline & & Missing & 0 & 0 & 0 \\
\hline & \multicolumn{2}{|c|}{ Mean } & 2.9428 & 3.1596 & 2.9699 \\
\hline & \multicolumn{2}{|c|}{ Mode } & 3.00 & 3.00 & 3.00 \\
\hline & \multicolumn{2}{|c|}{ Std. Deviation } & 1.04565 & 2.45721 & .96729 \\
\hline
\end{tabular}


Table 16 shows the statistical analysis of the KEFLUS responses based on their appropriateness and correctness. The KEFLUS sociopragmatic and pragmalinguistic competence mean scores were very similar, although the KEFLUS participants demonstrated higher pragmatic competence than linguistic. Overall, participant responses were deemed appropriate.

\subsubsection{Refusal}

Table 17. Appropriate pragmatic and linguistic forms (refusal)

\begin{tabular}{llllll}
\hline Questions & & & Refusal 1 & Refusal 2 & Refusal 3 \\
\hline Sociopragmatics & $\mathrm{N}$ & Valid & 332 & 332 & 332 \\
& & Missing & 0 & 0 & 0 \\
& Mean & & 3.0783 & 3.0060 & 2.4910 \\
& Mode & 3.00 & 3.00 & 2.00 \\
& Std. Deviation & 1.16074 & 1.19918 & 1.06435 \\
\hline Pragmalinguistics & $\mathrm{N}$ & Valid & 332 & 332 & 332 \\
& & Missing & 0 & 0 & 0 \\
& Mean & & 3.1506 & 3.0422 & 2.8524 \\
& Mode & 3.00 & 3.00 & 2.00 \\
& Std. Deviation & 1.09167 & 1.10123 & 1.09070 \\
\hline
\end{tabular}

Table 17 shows the mean, mode, and standard deviation of the KEFLUS responses when performing the speech act of refusal. Comparing the three situations, the KEFLUS demonstrated less competence during the third situation, although the data suggest that their responses were appropriate overall. This supports the findings of Bella (2014) and Taguchi $(2006,2007)$, who found that request and refusal performance improves with increased language proficiency.

\subsection{Third Research Question}

Third Research Question: Do male and female KEFLUS utilize significantly different strategies when performing the speech acts of suggestion and refusal? If so, how are their strategy patterns different?

\subsubsection{Suggestion}

Table 18. Individual strategies used by male and female (suggestion 1)

\begin{tabular}{llll}
\hline Type & Strategy & Male & Female \\
\hline Direct & & & \\
\hline & Performatives & $20(60.6 \%)$ & $26(52.0 \%)$ \\
& Imperatives & $5(15.1 \%)$ & $3(6.0 \%)$ \\
& Negative imperative & $0(0 \%)$ & $4(8.0 \%)$ \\
\hline Conventionally indirect & & & $16(32.0 \%)$ \\
& Interrogative forms & $7(21.3 \%)$ & $1(2.0 \%)$ \\
\hline Total & Conditional & $1(3.0 \%)$ & $50(100 \%)$ \\
\hline
\end{tabular}

Table 19. Individual strategies used by male and female (suggestion 2)

\begin{tabular}{llll}
\hline Type & Strategy & Male & Female \\
\hline Direct & & & \\
\hline & Performatives & $13(39.4 \%)$ & $22(44.0 \%)$ \\
& Noun of suggestion & $2(6.1 \%)$ & $0(0 \%)$ \\
& Imperatives & $7(21.2 \%)$ & $10(20.0 \%)$ \\
& Negative imperative & $0(0 \%)$ & $1(2.0 \%)$ \\
\hline Conventionally indirect & & & $17(34.0 \%)$ \\
& Interrogative forms & $9(27.2 \%)$ & $0(0 \%)$ \\
& Should & $2(6.1 \%)$ & $(2.0 \%)$ \\
\hline Total & Conditional & $0(0 \%)$ & $50(100 \%)$ \\
\hline
\end{tabular}


Table 20. Individual strategies used by male and female (suggestion 3)

\begin{tabular}{llll}
\hline Type & Strategy & Male & Female \\
\hline Direct & & & \\
\hline & Performatives & $21(63.6 \%)$ & $30(60.0 \%)$ \\
& Imperatives & $5(15.2 \%)$ & $8(16.0 \%)$ \\
& Negative imperative & $1(3.0 \%)$ & $1(2.0 \%)$ \\
\hline Conventionally indirect & & & $8(16.0 \%)$ \\
& Interrogative forms & $2(6.1 \%)$ & $3(6.0 \%)$ \\
& Should & $2(6.0 \%)$ & $0(0 \%)$ \\
\hline Indirect & Conditional & $1(3.0 \%)$ & $0(0 \%)$ \\
\hline \multicolumn{5}{l}{ Total } & Hints & $1(3.0 \%)$ & $50(100 \%)$ \\
\hline
\end{tabular}

Tables 18, 19, and 20 compare male and female KEFLUS strategies when performing suggestions One, Two, and Three, respectively. The combined findings of these tables show that male and females both opted for direct and explicit suggestion strategies, which supports the findings of Pishghadam and Sharafadini (2011), who found that native speakers of Farsi employed direct forms more than any other type when making suggestions.

Moreover, the researchers noticed that the male and female participants preferred performative strategies, such as 'I suggest', 'I advise' and 'I recommend,' to interrogative or imperative forms.

Table 21. Independent-samples t-test (suggestion)

\begin{tabular}{llllll}
\hline & Gender & N & Mean & Std. Deviation & Sig. (2-tailed) \\
\hline Suggestion 1 & male & 264 & 2.8826 & 1.08806 & .891 \\
& female & 400 & 2.8950 & 1.17363 & .664 \\
\hline Suggestion 2 & male & 264 & 3.1970 & 1.55722 & 2.31178 \\
& female & 400 & 3.2675 & .98239 & .850 \\
\hline Suggestion 3 & male & 264 & 3.0909 & 1.10337 & \\
& female & 400 & 3.0750 & \\
\hline
\end{tabular}

The researchers conducted an independent sample t-test to evaluate potential differences in sociopragmatic and pragmatic linguistic competence between the male and female KEFLUS participants. As demonstrated by Table 21 , no significant difference was found between males and females.

\subsubsection{Refusal}

Table 22. Individual strategies used by males and females (refusal of a request)

\begin{tabular}{lll}
\hline Strategy & Male & Female \\
\hline Direct & & \\
\hline No & $2(6.1 \%)$ & $3(6.0 \%)$ \\
Negative willingness/ ability & $9(27.3 \%)$ & $12(24.0 \%)$ \\
\hline Indirect & & \\
\hline Regret & $4(12.1 \%)$ & $6(12.0 \%)$ \\
Excuse, reason, explanation & $1(3.0 \%)$ & $7(14.0 \%)$ \\
Regret, reason and Alternative & $4(12.1 \%)$ & $8(16.0 \%)$ \\
Regret \& alternative & $0(0 \%)$ & $1(2.0 \%)$ \\
Statement of alternative & $0(0 \%)$ & $2(4.0 \%)$ \\
Regret and reason & $13(39.4 \%)$ & $9(18.0 \%)$ \\
conditional & $0(0 \%)$ & $1(2.0 \%)$ \\
wish & $0(0 \%)$ & $1(2.0 \%)$ \\
\hline Total & $33(100 \%)$ & $50(100 \%)$ \\
\hline
\end{tabular}


Table 23. Individual strategies used by males and females (refusal of a suggestion)

\begin{tabular}{lll}
\hline Strategy & Male & Female \\
\hline Direct & & \\
\hline No & $5(15.2 \%)$ & $9(18.0 \%)$ \\
Negative willingness/ ability & $17(51.5 \%)$ & $19(38.0 \%)$ \\
Indirect & & \\
Regret & $2(6.1 \%)$ & $9(18.0 \%)$ \\
Excuse, reason, explanation & $0(0 \%)$ & $2(4.0 \%)$ \\
Regret, reason and Alternative & $0(0 \%)$ & $2(4.0 \%)$ \\
Regret and reason & $8(24.2 \%)$ & $5(10.0 \%)$ \\
Wish & $1(3.0 \%)$ & $1(2.0 \%)$ \\
\hline Adjuncts to refusal & & $3(6.0 \%)$ \\
\hline Positive feeling & $0(0 \%)$ & $50(100 \%)$ \\
\hline Total & $33(100 \%)$ & \\
\hline
\end{tabular}

Table 24. Individual strategies used by males and females (refusal of an offer)

\begin{tabular}{lll}
\hline Strategy & Male & Female \\
\hline Direct & & $3(6.0 \%)$ \\
\hline No & $2(6.1 \%)$ & $26(52.0 \%)$ \\
Negative willingness/ ability & $18(54.5 \%)$ & \\
\hline Indirect & & $7(14.0 \%)$ \\
\hline Regret & $1(3.0 \%)$ & $2(4.0 \%)$ \\
Excuse, reason, explanation & $1(3.0 \%)$ & $4(8.0 \%)$ \\
Regret and reason & $6(18.2 \%)$ & \\
\hline Adjuncts to refusal & & $5(10.0 \%)$ \\
\hline Positive feeling & $4(12.1 \%)$ & $3(6.0 \%)$ \\
Gratitude/ appreciation & $1(3.0 \%)$ & $50(100 \%)$ \\
\hline Total & $33(100 \%)$ &
\end{tabular}

Tables 22, 23, and 24 compare male and female KEFLUS strategies when refusing requests, suggestions, and offers, respectively. As was observed to be the case with the suggestion scenarios, males and females favoured direct and explicit strategies more than any other category when refusing. These findings are contrary to those of Lin (2014), whose Chinese EFL and American NSE participants tended to use direct strategies least when refusing.

Both males and females preferred 'negative willingness' strategies, such as 'I can't', over direct 'no' refusals. This result may be due to an understanding that saying 'no' is more face-threatening than utilizing a 'negative willingness' form (Chang, 2009). Females used a greater variety of strategies overall.

Table 25. Independent sample t-test (refusal)

\begin{tabular}{llllll}
\hline & Gender & $\mathrm{N}$ & Mean & Std. Deviation & Sig. (2-tailed) \\
\hline Refusal 1 & male & 264 & 3.1629 & 1.09613 & .369 \\
& female & 400 & 3.0825 & 1.14629 & .206 \\
\hline Refusal 2 & male & 264 & 2.9545 & 1.18523 & \\
& female & 400 & 3.0700 & 1.12618 & .454 \\
\hline Refusal 3 & male & 264 & 2.6326 & 1.13927 & \\
& female & 400 & 2.6975 & 1.06010 & \\
\hline
\end{tabular}

The researchers used an independent sample t-test to compare the appropriateness (linguistically and pragmatically) of responses made by male and female KEFLUS participants. The data shown in Table 25 shows no significant difference between males and females, although females showed more competence in their responses.

\subsection{Fourth Research Question}

Fourth research question: Is there a significant difference between private and state universities with regard to their effectiveness at teaching appropriate linguistic and pragmatic forms (such as permission, request, 
suggestion, opinion, apology, invitation, refusal, offer, questioning, and advising)? If so, how do they differ?

Researchers used an independent sample t-test to determine significant differences between KEFLUS of private and state universities.

\subsubsection{Suggestion}

Table 26. Independent samples t-test of the speech act of suggestion

\begin{tabular}{llllll}
\hline & Type of University & $\mathrm{N}$ & Mean & Std. Deviation & Sig. (2-tailed) \\
\hline Suggestion 1 & State & 464 & 2.7974 & 1.12785 & .001 \\
& Private & 200 & 3.1050 & 1.14038 & \\
\hline Suggestion 2 & State & 464 & 3.0668 & 1.08089 & .001 \\
& Private & 200 & 3.6400 & 3.31290 & \\
\hline Suggestion 3 & State & 464 & 3.0366 & 1.06219 & .097 \\
& Private & 200 & 3.1850 & 1.03738 & \\
\hline
\end{tabular}

Table 26 illustrates differences in pragmatic and linguistic competence with regard to their responses when making Suggestions 1, 2, and 3. The t-test results reveal a statistically significant difference in competency between participants from the two categories during Situations 1 and 2, with private university students demonstrating a higher competence when compared to state university students. The difference in competency between the two groups in Situation 3 was not significant.

\subsubsection{Refusal}

Table 26. Independent samples t-test of the speech act of refusal

\begin{tabular}{llllll}
\hline & Type of University & $\mathrm{N}$ & Mean & Std. Deviation & Sig. (2-tailed) \\
\hline Refusal 1 & state & 464 & 3.0819 & 1.13922 & .257 \\
& private & 200 & 3.1900 & 1.09540 & \\
\hline Refusal 2 & state & 464 & 2.8922 & 1.15590 & .000 \\
& private & 200 & 3.3300 & 1.08025 & .014 \\
\hline Refusal 3 & state & 464 & 2.6034 & 1.08099 & 1.10326 \\
& private & 200 & 2.8300 & & \\
& & & & \\
\hline
\end{tabular}

As seen in Table 27, independent sample t-test data comparing responses from private and state university students demonstrates a statistically significant difference in competency between the two groups when they performed refusals in the three situations. As was the case when performing suggestions, private university students showed more pragmatic and linguistic competence than state students did when performing refusals.

\section{Conclusion}

The successful understanding and performance of L2 speech acts requires strong pragmatic competence. This study investigated the pragmatic competence of KEFLUS by analysing their performance of the speech acts of suggestion and refusal.

This study followed a mixed research methodology — both the qualitative and quantitative methods were used. A quantitative method was used to investigate the strategies and potential strategy patterns KEFLUS employ in their L2 when performing the speech acts of suggestion and refusal. Additionally, the study compared male and female strategies, and investigated potential differences between private university students and state university students. A qualitative method was used to evaluate the appropriateness of the strategies KEFLUS chose when performing suggestions and refusals.

Quantitatively, data were coded and analysed based on the analytical framework of the Martinez-Flor (2005) coding scheme of speech act of suggestion, and the Beebe et al. (1990) taxonomy of refusals. From a qualitative point of view, this study investigated the appropriateness of language use by KEFLUS, both sociopragmatically and pragmalinguistically, by evaluating their responses based on the ratings scale created by the researchers. Once the researchers had scored all KEFLUS and NSE responses, they computed and tabulated the data using SPSS version 22.

Data from this study reveals distinct differences between how the KEFLUS and NSE perform the speech acts of 
suggestion and refusal. Although participants from both groups were observed using various strategies when making suggestions and refusals, the KEFLUS utilized direct and explicit strategies more often than did the NSE participants. The NSE group utilized strategies that were more polite and implicit.

With regard to sociopragmatic and pragmatic competence, KEFLUS responses were rated based on their function (sociopragmatics) and form (pragmalinguistics). Based on this qualitative analysis, KEFLUS responses were deemed appropriate overall.

With respect to gender, male KEFLUS employed direct and explicit strategies more often than females, while females showed more competence in their language usage. The study found no significant difference between male and female KEFLUS in terms of the appropriateness of the speech acts they performed.

Regarding state and private university students, an independent sample t-test was used to compare mean scores from both university types. The t-test results show a statistically significant difference between the scores of these two groups, with the private university students demonstrating a higher level of pragmatic and linguistic competence in performing the speech acts in English. These findings suggest that private university English programs are more effective than state programs. The researchers observed that private university instructors were more attentive to their students. This observation concurs with $\mathrm{Li}$ (2010), who found that Cantonese students in their L2 utilized a narrower range of suggestive strategies than Australian NSE students.

\section{References}

Abed, A. (2011). Pragmatic Transfer in Iraqi EFL Learners' Refusals. International Journal of English Linguistics, 1(2), 166. https://doi.org/10.5539/ijel.v1n2p166

Al-Kahtani, S. (2005). Refusals Realizations in Three Different Cultures: A Speech Act Theoretically-ased Cross-cultural Study. Journal of King Saud University, 18, 35-57.

Austin, J. L. (1962). How to Do Things with Words. Oxford, England: Calderon Press.

Austin, J. L. (1975). How to Do Things with Words. Harvard University Press. Cambridge, Massachusetts. https://doi.org/10.1093/acprof:oso/9780198245537.001.0001

Banerjee, J., \& Carrell, P. L. (1988). Truck in your shirt, your squid: Suggestions in ESL. Language Learning 38(3), 313-364. https://doi.org/10.1111/j.1467-1770.1988.tb00416.x

Beebe, L. M., Takahashi, T., \& Uliss-Weltz, R. (1990). Pragmatic transfer in ESL refusals. In R. C. Scarcella, E. S. Andersen, \& S. D. Krashen (Eds.), Developing Communicative Competence in a Second Language (pp. 55-73). New York: Newbury House.

Bella, S. (2014). Developing the ability to refuse: A cross-sectional study of Greek FL refusals. Journal of Pragmatics, 61, 35-62. https://doi.org/10.1016/j.pragma.2013.11.015

Brown, P., \& Levinson, S. C. (1987). Politeness: Some Universals in Language Use. Cambridge: Cambridge University Press.

Chang, Y. F. (2009). How to say no: An analysis of cross-cultural difference and pragmatic transfer. Language Sciences, 31, 477-493. https://doi.org/10.1016/j.langsci.2008.01.002

Cohen, A. (1996). Developing the ability to perform speech acts. SSLA, 18, 253-267. https://doi.org/10.1017/S027226310001490X

Cohen, A., \& Olshtain, E. (1983). Apology: A speech act set. In N. Wolfson \& E. Judd (Eds.), Sociolinguistics and Language Acquisition (pp. 18-35). Rowley, MA: Newbury House.

Fraser, B. (1990). Perspectives on politeness. Journal of Pragmatics, 14(2), 219-236. https://doi.org/10.1016/0378-2166(90)90081-N

Han, T. (2016). Realization of Speech Acts of Refusals and Pragmatic Competence by Turkish EFL Learners. The Reading Matrix, 16(1), 161. Retrieved from http://www.readingmatrix.com/files/14-j4156s4z.pdf

Haverkate, H. (1984). Speech Acts, speakers and hearers [Pragmatics and Beyond 4]. Amsterdam: John Benjamins Pub. Company. https://doi.org/10.1075/pb.v.4

Li, E. S. (2010). Making suggestions: A contrastive study of young Hong Kong and Australian students. Journal of pragmatics, 42, 598-616._https://doi.org/10.1016/j.pragma.2009.07.014

Lin, M. (2014). An Interlanguage Pragmatic Study on Chinese EFL Learners' Refusal: Perception and Performance. Journal of Language Teaching and Research, 5(3), 642-653. https://doi.org/10.4304/jltr.5.3.642-653 
Martínez-Flor, A. (2005). A theoretical review of the speech act of suggesting: towards a taxonomy for its use in FLT. Revista Alicantina de Estudios Ingleses, 18, 167-187. https://doi.org/10.14198/raei.2005.18.08

Martinez-Flor, A., \& Uso-Juan, E. (2010). Speech act performance: Ttheoretical, empirical and methodological issues. Amsterdam: John Benjamins Pub. Company. https://doi.org/10.1075/11lt.26

McKay, S., \& Hornberger, N. H. (1996). Sociolinguistics and Language Teaching. Cambridge: CUP.

Moaveni, H. (2014). A Study of Refusal Strategies by American and International Students at an American University. Unpublished doctoral dissertation, Minnesota State University, Mankato.

Pishghadam, R., \& Sharafadini, M. (2011). A contrastive study into the realization of suggestion speech act: Persian vs. English. Canadian Social Science, 7(4), 230-239.

Sadler, R. W., \& Eroz, B. (2001). "I refuse you!" An examination of English refusals by native speakers of English, Lao, and Turkish. Arizona Working Papers in SLAT, 9, 53-80.

Searle, J. R. (1976). The Classification of Illocutionary Acts. Language in Society, 5(1), 1-24. https://doi.org/10.1017/S0047404500006837

Taguchi, N. (2006). Analysis of appropriateness in a speech act of request in L2 English. Pragmatics, 16(4), 513-533. https://doi.org/10.1075/prag.16.4.05tag

Taguchi, N. (2007). Task Difficulty in Oral Speech Act Production. Applied Linguistics, 28, 113-135. https://doi.org/10.1093/applin/aml051

Thomas, J. (1983). Cross-cultural pragmatic failure. Applied Linguistics, 4, 91-112. https://doi.org/10.1093/applin/4.2.91

Wannaruk, A. (2008). Pragmatic transfer in Thai EFL refusals. RELC, 39(3), 318-337. https://doi.org/10.1177/0033688208096844

Yule, G. (1996). Pragmatics. Oxford: Oxford University Press.

\section{Copyrights}

Copyright for this article is retained by the author, with first publication rights granted to the journal.

This is an open-access article distributed under the terms and conditions of the Creative Commons Attribution license (http://creativecommons.org/licenses/by/4.0/). 